\title{
Bridge Deck Replacement for Minimum Expected Cost Under Multiple Reliability Constraints
}

\author{
Mark G. Stewart, M.ASCE${ }^{1}$; Allen C. Estes, M.ASCE${ }^{2}$; and Dan M. Frangopol, F.ASCE ${ }^{3}$
}

\begin{abstract}
The present paper investigates the effect of limit state selection (strength versus serviceability) on bridge deck life-cycle costs and thus on optimal repair strategies. Such a comparison may then help determine whether safety or functionality (or both) are important criteria when optimizing bridge life-cycle performance and costs. The structural element under consideration is a reinforced concrete bridge deck; namely, a State Highway Bridge in Colorado. Two limit states are considered: ultimate strength and serviceability. The exceedence of either of the limit states considered herein will result in deck replacement; namely, if the reliability index falls below a target reliability index or if widespread cracking and spalling occurs. The life-cycle cost analysis includes expected replacement costs as well as the random variability of material properties, loads, section dimensions, model errors, chloride penetration, and corrosion rates. Life-cycle costs can then be compared for strength and serviceability limit state violations. Life-cycle costs for deck replacement based on a serviceability limit state were generally larger than those obtained for the strength limit states. Hence, an unrealistically optimistic life-cycle cost will result when serviceability is not included in the analysis.
\end{abstract}

CE Database subject headings: Corrosion; Limit states; Life cycle cost; Reliability; Concrete; Bridge decks; Rehabilitation; Replacement.

\section{Introduction}

Decision-making models utilizing present and anticipated structural reliabilities provide rational decision-making tools for structural assessment and optimizing design specifications, inspections, and repair strategies (e.g., Frangopol 1997; Stewart 1998; Frangopol and Furuta 2001). Recent advances have been made in the reliability-based optimization of inspection, maintenance, and repair strategies for deteriorating structures; these usually consider strength limit states where loss of safety is the main criterion for decision making (e.g., Mori and Ellingwood 1994a,b; ThoftChristensen 1995; Estes and Frangopol 1999; Faber and Sorensen 1999). Some studies have considered the time-dependent reliability of structures for multiple limit states (strength, serviceability) and their interaction (e.g., Stewart and Rosowsky 1998; Vu and Stewart 2000) and only few studies have considered serviceability limit states for decision making (e.g., Troive and Sundquist 1998; Holicky and Mihashi 1999; Estes and Frangopol 2000), but these tend to consider service life (need for repairs) to have ended when corrosion is initiated or first (hairline) cracking detected. This is

\footnotetext{
${ }^{1}$ Associate Professor, Centre for Infrastructure Performance and Reliability, The Univ. Newcastle, NSW 2308, Australia (corresponding author). E-mail: mark.stewart@newcastle.edu.au

${ }^{2}$ Associate Professor, Dept. of Civil and Mechanical Engineering, United States Military Academy, West Point, NY 10996.

${ }^{3}$ Professor, Dept. of Civil, Environmental and Architectural Engineering, Univ. of Colorado, Boulder, CO 80309-0428.
}

quite conservative, and so time to severe cracking and spalling is considered as a more realistic criterion for life-cycle cost optimization of repair strategies (Stewart and Rosowsky 1998; Stewart 2001; Thoft-Christensen 2001; Stewart et al. 2002; Vu and Stewart 2002).

Serviceability and other functional failures greatly outnumber catastrophic failures (i.e., collapse) and so it is reasonable to assume that serviceability failures constitute a large source of economic loss. For reinforced concrete (RC) structures, the occurrence of longitudinal cracking (coincident cracks following the line of the reinforcement caused by reinforcement corrosion), delamination and spalling of the concrete cover is referred to herein as a serviceability failure. Serviceability failures result in the need for repairs, replacement, or more frequent inspections to monitor further deterioration. Clearly, this contributes considerably to the financial resources that need to be allocated to ameliorate these effects of deterioration.

The present paper will investigate the effect of limit state selection on life-cycle costs of bridges and thus on optimal repair strategies. Two limit states are considered: ultimate strength and serviceability (severe corrosion-induced cracking). Such a comparison may then help determine whether safety or functionality (or both) are important criteria when optimizing bridge life-cycle performance and costs. The structural element under consideration is a RC bridge deck; namely, a State Highway Bridge in Colorado. Life-cycle costs can then be compared for strength and serviceability limit state violations and observations made as to how limit state selection may affect replacement strategies.

\section{Colorado Bridge E-17-AH}

The life-cycle cost analyses will be applied to an existing structure that has been subject to a number of prior reliability and optimization studies (Frangopol 1997; Estes and Frangopol 


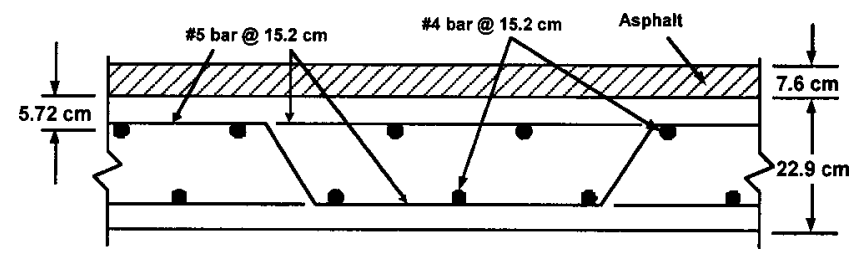

Fig. 1. Reinforced concrete slab from bridge E-17-AH

2001a); namely, the State Highway Bridge E-17-AH located in Denver, Colo. This bridge has three simple spans of equal length $(13.3 \mathrm{~m})$ with a total length of $42.1 \mathrm{~m}$. The deck consists of a 229 $\mathrm{mm}$ RC slab topped by $76 \mathrm{~mm}$ of asphalt. The (uncoated) rebars are of $15.9 \mathrm{~mm}$ diameter and spaced at $152 \mathrm{~mm}$ centers (see Fig. 1). The roadway width is $12.2 \mathrm{~m}$ with $1.5 \mathrm{~m}$ pedestrian sidewalks. The slab for each simple span is supported by nine standardrolled compact, noncomposite, steel girders. The bridge has two lanes of traffic in each direction with an average daily traffic (ADT) of 8,500 vehicles/day. More details of this bridge are described in Estes (1997).

\section{Component Reliability}

The component of interest will be the RC bridge deck and two limit states are considered: ultimate strength and serviceability.

- $g_{i}(1)$ flexural failure of slab $i$-ultimate strength limit state; and

- $g(2)$ severe corrosion-induced cracking of all slabsserviceability limit state.

The repeated application of de-icing salts is the cause of deck deterioration.

\section{Ultimate Strength Limit State}

The limit state for flexural failure of slab $g_{i}(1)$ for one-way bending between the girders is

$$
\begin{aligned}
g_{i}(1)= & M_{\text {capacity }}-M_{\text {demand }}=\operatorname{ME}\left[0.349 \lambda_{\text {st }} f_{y} \lambda_{d}-\frac{0.3844 \lambda_{\mathrm{st}}^{2} f_{y}^{2}}{244.8 f_{c}^{\prime}}\right\rfloor \\
& -0.137 \lambda_{\text {asph }}-0.471 \lambda_{\text {conc }}-4.26 \lambda_{\text {truck }}
\end{aligned}
$$

where $M_{\text {capacity }}=$ structural resistance of the slab; $M_{\text {demand }}=$ peak dead and live (truck) load effect; and other variables are described in Table 1. Note that Eq. (1) refers to the governing limit state of all eight spans supported by the nine girders. Corrosion-induced bridge deck deterioration will cause a reduction in cross-sectional area of the rebars $\left(A_{\mathrm{st}}\right)$, resulting in a decrease in structural resistance over time.

The deck is considered as a series system comprised of three bridge spans. This means that structural failure occurs if the limit state $\left[g_{i}(1)\right]$ of any one span is exceeded. The maximum truck load is determined using a live-load model, which predicts maximum truck moments and shears developed by Nowak (1993). When the ADT is known, extreme value statistics are applied to actual bridge traffic based on the data from a single truck. As more trucks go over the bridge, there is an increased probability that an overloaded truck will cross the bridge.

\section{Serviceability Limit State}

The limit state for time to severe cracking and spalling at time $T$ is

$$
g(2)=\left(T_{i}+T_{\mathrm{sp}}\right)-T
$$

where $T_{i}=$ time to corrosion initiation; and $T_{\mathrm{sp}}=$ time for cracks to propagate to the limit crack width. The time to cracking and spalling referred to herein is the time when concrete cover cracking reaches a limit crack width and is estimated based on results from accelerated corrosion testing of RC slabs. The corrosion-induced cracks occurred on the concrete surface above and parallel to the rebars. The various stages of time-dependent crack propagation (crack growth) can be divided into two stages: (1) crack initiation $\left(T_{1 \mathrm{st}}\right)$ and (2) crack propagation $\left(T_{\mathrm{ser}}\right)$ (see Fig. 2) where $T_{\mathrm{sp}}$ $=T_{1 \mathrm{st}}+T_{\mathrm{ser}}$.

There are few models that can predict corrosion-induced crack initiation and propagation, and these are limited to crack widths

\begin{tabular}{|c|c|c|c|c|}
\hline Parameter & Notation & Mean & $\begin{array}{c}\text { Coefficient of } \\
\text { variation }\end{array}$ & Distribution \\
\hline Uncertainty: $A_{\mathrm{st}}$ & $\lambda_{\text {st }}$ & 1.0 & 0.015 & Normal \\
\hline Uncertainty: effective depth & $\lambda_{d}$ & 1.0 & 0.02 & Normal \\
\hline Uncertainty: asphalt weight & $\lambda_{\text {asph }}$ & 1.0 & 0.25 & Normal \\
\hline Uncertainty: concrete weight & $\lambda_{\text {conc }}$ & 1.05 & 0.105 & Normal \\
\hline Uncertainty: truck weight & $\lambda_{\text {truck }}$ & 1.38 & 0.166 & Normal \\
\hline Model error: flexure & ME & 1.02 & 0.061 & Normal \\
\hline Yield stress & $f_{y}$ & $386.1 \mathrm{MPa}$ & 0.11 & Normal \\
\hline Top cover & $c$ & $57.2 \mathrm{~mm}$ & 0.15 & Normal \\
\hline Concrete composition strength & $f_{c}^{\prime}$ & $19 \mathrm{MPa}$ & 0.19 & Normal \\
\hline Concrete tensile strength & $f_{\mathrm{ct}}^{\prime}$ & $0.53 \sqrt{f_{c}^{\prime}}$ & 0.13 & Normal \\
\hline Diffusion coefficient & $D$ & $3.5 \mathrm{E}-8 \mathrm{~cm}^{2} / \mathrm{s}$ & 0.071 & Normal \\
\hline Surface chloride concentration & $C_{0}$ & $3.78 \mathrm{~kg} / \mathrm{m}^{3}(1.08 \%)$ & 0.067 & Normal \\
\hline Threshold chloride concentration & $C_{\mathrm{cr}}$ & $1.4 \mathrm{~kg} / \mathrm{m}^{3}(0.4 \%)$ & 0.125 & Normal \\
\hline Time to corrosion initiation & $T_{i}$ & 19.6 years & 0.38 & Normal \\
\hline Corrosion rate & $1_{\text {corr }}$ & $2.5 \mu \mathrm{A} / \mathrm{cm}^{2}$ & 0.19 & Uniform \\
\hline
\end{tabular}

Table 1. Statistical Parameters for Dimensional, Material, Loading, and Corrosion Variables (Thoft-Christensen et al. 1997; Estes and Frangopol 1999) 


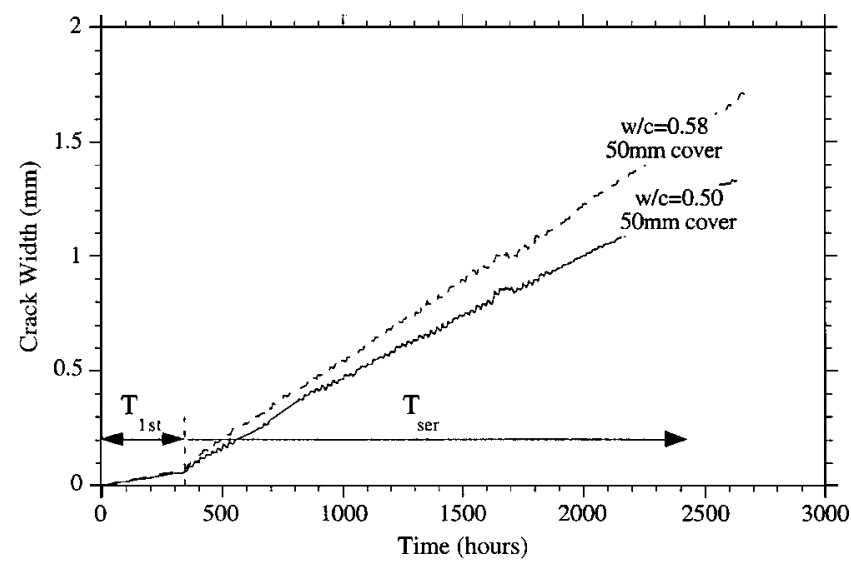

Fig. 2. Accelerated corrosion testing results for crack propagation (corrosion rate $=100 \mu \mathrm{A} / \mathrm{cm}^{2}$ )

not exceeding $0.5 \mathrm{~mm}$ mainly because it is generally accepted that the service life of a structure is reduced considerably only if cracks with widths exceeding $0.3-0.5 \mathrm{~mm}$ are not repaired-this is essentially a durability limit state. On the other hand, Sakai et al. (1999) stated that a limit crack width of $0.8 \mathrm{~mm}$ is recommended for serviceability (aesthetics) requirements. The limit crack width that would necessiate repair is not clear, but is likely to be greater than $0.3-0.4 \mathrm{~mm}$. Hence, in the present paper, limit crack widths of 0.5 and $1.0 \mathrm{~mm}$ will be considered.

A limited accelerated corrosion testing program has been conducted at The Univ. of Newcastle during 1999-2001 comprising eight $700 \mathrm{~mm} \times 1,000 \mathrm{~mm}$ concrete specimens to simulate reinforcement corrosion of a section of a typical bridge deck ( $\mathrm{Vu}$ and Stewart 2002; Vu 2003). The tests investigated the effect of concrete cover and water-cement ratio on corrosion-induced cracking. The testing program is being used to develop crack initiation and propagation models. A constant corrosion rate of approximately $i_{\text {corr }}=100 \mu \mathrm{A} / \mathrm{cm}^{2}$ was applied to accelerate the corrosion process. This high current allowed for a short period of testing (2-4 months). Most corroding structures experience corrosion rates of $0.1-10 \mu \mathrm{A} / \mathrm{cm}^{2}$ (Dhir et al. 1994). Given the limited experimental data collected to date, the crack initiation and propagation models proposed herein are only preliminary.

\section{Crack Initiation $\left(T_{1 s t}\right)$}

The test results show that crack initiation (hairline cracking of $0.05 \mathrm{~mm}$ width) can be reasonably predicted by the Liu and Weyers (1998) model. In the Liu and Weyers model, the time to crack initiation is the time when stresses resulting from the expansion of corrosion products exceed the tensile strength of concrete. The critical amount of corrosion products needed to cause first cracking consists of two parts: (1) the amount of corrosion products required to fill the total porous zone around the steel/concrete interface (i.e., free expansion within interfacial transition zone which is up to $35-50 \mu \mathrm{m}$ wide) and (2) the additional amount of corrosion products then needed to generate the critical tensile stresses. The time to cracking is influenced by corrosion rate, cover, concrete quality, rebar size, and material properties.

\section{Crack Propagation $\left(T_{\text {ser }}\right)$}

An empirical model of corrosion-induced crack propagation was inferred from experimental results. The time for cracking of concrete cover to reach a limit crack width $\left(w_{\text {lim }}\right)$ is thus

$$
\begin{aligned}
T_{\text {ser }}=0.0167 i_{\text {corr }}^{-1.1} \times & \left\lfloor 42.9(\mathrm{wc} / C)^{-0.54}+\left(\frac{w_{\text {lim }}-0.3}{0.0062}\right)^{1.5}\right\rfloor \\
& w_{\text {lim }} \geqslant 0.3 \mathrm{~mm}
\end{aligned}
$$

where $T_{\text {ser }}=$ time since crack initiation (years); $w c=$ watercement ratio; $C=$ concrete cover $(\mathrm{mm})$; and $i_{\text {corr }}=$ corrosion rate $\left(\mathrm{mA} / \mathrm{cm}^{2}\right)$ assumed constant with time. The model is valid for 16 $\mathrm{mm}$ diameter rebars. The water-cement ratio is correlated to concrete compressive strength $\left(f_{c}^{\prime}\right)$ by the use of Bolomey's formula. See $\mathrm{Vu}$ (2003) for more details.

There is some evidence to suggest that cracks propagate slower as corrosion rate increases (Alonso et al. 1998), possibly because a higher rate of loading induces lower deformations. This suggests that crack propagation is more complex than previously thought and that the rate of loading of stress during crack propagation is an important variable. A correction factor was not included in the model of crack propagation. Work is continuing to develop mechanics-based predictive models (as opposed to the empirical or "best-fit" model shown herein) suitable for predicting crack initiation and propagation.

\section{Deterioration and Time-Dependent Reliabilities}

The deterioration process consists of two stages: corrosion initiation and corrosion propagation. If the bridge is exposed to regular applications of de-icing salts then chloride-induced corrosion can be expected.

\section{Corrosion Initiation}

Two approaches were used to determine the statistics for time to corrosion initiation:

1. U.S. Army Corps of Engineers point-estimate method (USACE 1992); and

2. Monte Carlo simulation analysis of Fick's second law of diffusion.

Both analyses use Fick's second law of diffusion where the chloride content $[C(x, t)]$ at a distance $x$ from the concrete surface at time $t$ is

$$
C(x, t)=C_{0}\left[1-\operatorname{erf}\left(\frac{x}{2 \sqrt{t D}}\right)\right\rfloor
$$

where $C_{0}=$ surface chloride concentration $\left(\mathrm{kg} / \mathrm{m}^{3}\right.$ of concrete); $D=$ diffusion coefficient $\left(\mathrm{cm}^{2} / \mathrm{s}\right)$; and erf=error function. The parameters used in Eq. (4) are derived from long-term measurements (many years) and so are not influenced by seasonal effects.

For the State Highway Bridge E-17-AH, Estes and Frangopol (1999) used the U.S. Army Corps of Engineers point-estimate method to predict the mean and standard deviation of time to corrosion initiation of the RC deck as 19.6 and 7.5 years, respectively.

For the same RC deck, a Monte Carlo simulation analysis reveals a mean and standard deviation times to corrosion initiation of 23.4 and 15.8 years, respectively (median of 19.0 years). The random variables used to calculate time to corrosion initiation were cover, diffusion coefficient, surface chloride concentration, and threshold chloride concentration using statistical parameters taken from Thoft-Christensen et al. (1997) (see Table 1). Note that most of these statistical parameters are similar to those used in previous work (Estes and Frangopol 1999). Both analyses for time to corrosion initiation are in broad agreement so the Estes and Frangopol (1999) results for time to initiation will be used in the present analysis. 


\section{Corrosion Propagation}

The strength analysis assumes that corrosion propagation will reduce the cross-sectional area of reinforcing steel, resulting in a time-dependent reduction in flexural capacity of the bridge deck. Pitting corrosion is not included in this analysis. Since pitting is spatially distributed it is likely that pitting will not significantly influence structural capacity at any given cross section. At any cross section, it is probable that only several bars will be subject to pitting corrosion while others will see very little corrosion. Corrosion rate is assumed to be time-invariant (constant with time), again to be consistent with previous work (Estes and Frangopol 1999). However, Vu and Stewart (2000) suggest that the formation of rust products on the steel surface will reduce the diffusion of the iron ions away from the steel surface. Also, the area ratio between the anode and cathode is reduced. This suggests that the corrosion rate will reduce with time. Note also that this analysis assumes that the chloride diffusion coefficient is constant, whereas it is more likely to increase as concrete quality decreases (Vu and Stewart 2000).

\section{Structural Reliability}

Since the ultimate strength of the slab is considered a series system of three slabs (each supported by nine girders spanning 13.3 $\mathrm{m})$, the probability of structural failure at a point in time is

$$
p_{f_{\mathrm{sys}}}=\Phi\left(-\beta_{\mathrm{sys}}\right)=\operatorname{Pr}\left\{g_{1}(1) \leqslant 0 \cup g_{2}(1) \leqslant 0 \cup g_{3}(1) \leqslant 0\right\}
$$

where the system reliability index is denoted as $\beta_{\text {sys }}$. Because the correlation is so high between these three slabs (i.e., same load, same concrete source, same steel rebar source, same placement methods, same deterioration conditions), the reliability of one slab is almost identical to the reliability of the three-slab system. The reliability is time-dependent because: (1) the maximum expected truck size is increasing over time and (2) the rebar diameter of the flexural steel is deteriorating due to corrosion at a rate of $0.0232 i_{\text {corr }} \mathrm{mm} / \mathrm{year}$. Statistical parameters used in the evaluation of Eq. (5) are given in Table 1.

The probability that severe cracking and spalling $\left(p_{f_{\mathrm{cr}}}\right)$ will occur at time $T$ is defined herein as

$$
p_{f_{\mathrm{cr}}}=\Phi\left(-\beta_{\mathrm{cr}}\right)=\operatorname{Pr}\{g(2) \leqslant 0\}
$$

The statistical parameters for time to corrosion initiation are taken from Estes and Frangopol (1999). Monte Carlo simulation analysis is used to develop time to severe cracking and spalling $\left(T_{\mathrm{sp}}\right)$ considering limit crack widths of 0.5 and $1.0 \mathrm{~mm}$ and new crack propagation models described above. The mean and standard deviation of time to cracking/spalling are: (1) 6.3 and 1.2 years for a $0.5 \mathrm{~mm}$ limit crack width, respectively, and (2) 12.1 and 1.8 years for a $1.0 \mathrm{~mm}$ limit crack width, respectively. Note that the mean time to first cracking is only 2.1 years. A lognormal distribution closely fits the simulation results and is not rejected at the 5\% significance level using the Kolmogorov-Smirnov test (see Fig. 3).

Results of the Monte Carlo simulation conducted for the present study show that there is little correlation between time to corrosion initiation $\left(T_{i}\right)$ and time to cracking/spalling $\left(T_{\mathrm{sp}}\right)$. This is initially surprising; however, time to cracking is influenced by corrosion rate and concrete tensile strength, which do not affect the time to initiation model used herein. The only common parameter is cover. Hence, the correlation coefficient between the probability distributions $T_{i}$ and $T_{\mathrm{sp}}$ is only 0.19 .

The incidence of corrosion, cracking, and spalling of concrete

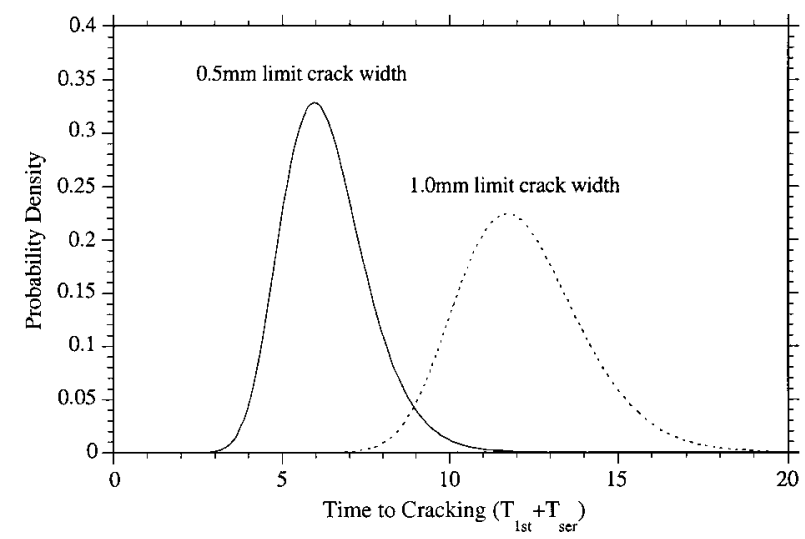

Fig. 3. Time to cracking (since time to corrosion initiation)

structures is not homogeneous across an entire structure as assumed herein. This is not surprising since concrete quality and concrete cover are known to vary spatially over the concrete surface, normally caused by different concrete batches and the variability of workmanship. The level of exposure to aggressive agents such as chlorides is also spatially variable. This will require the development of random field modeling that takes into account the spatial variability of corrosion initiation, propagation and cracking (e.g., Sterritt et al. 2001; Vu and Stewart 2001). This is an area of ongoing research.

\section{Repair Options and Life-Cycle Costs}

There are a large number of possible repair strategies available. Repairs may include patching of damaged areas, or if spalling is widespread then deck replacement may be the preferred deck rehabilitation procedure (Cady 1985). Hence, it is expected that exceedance of either of the limit states considered herein will result in deck replacement for all three spans. This scenario therefore assumes 100\% repair efficiency (i.e., bridge deck returned to "as new" condition).

Two independent criteria are used to determine deck replacement strategies. Hence, it is assumed herein that deck replacement will occur if:

1. Reliability index $\left(\beta_{\text {sys }}\right)$ falls below a target reliability index $\left(\beta_{T}\right)$ of 2.0. The target reliability of $\beta_{T}=2.0$ may appear low, but is the result of highly conservative assumptions with the load model. Less conservative assumptions would have resulted in target reliabilities in the range of $\beta_{T}=3.0-4.0$, which would have been more consistent with existing load case combinations.

2. Cracking and spalling occurs with reliability $\beta_{\mathrm{cr}}$. The reliability threshold $\left(\beta_{T}\right)$ for a serviceability limit state is necessarily less stringent as the consequences of failure are less dire. The spalling resulting from serviceability failure will disrupt traffic and create a more hazardous environment while a moment failure of the slab could cause loss of life. While this judgment would ultimately be left to the engineer or bridge manager, the repair in this study is targeted to when the serviceability failure is most likely to occur (i.e., when there is a $50-50$ chance of cracking and spalling) which equates to $\beta_{T}=0.0$.

For both scenarios it is assumed that the deck is replaced with that originally provided so deck replacement may reoccur during the remaining life of the structure (i.e., repair provides no improve- 


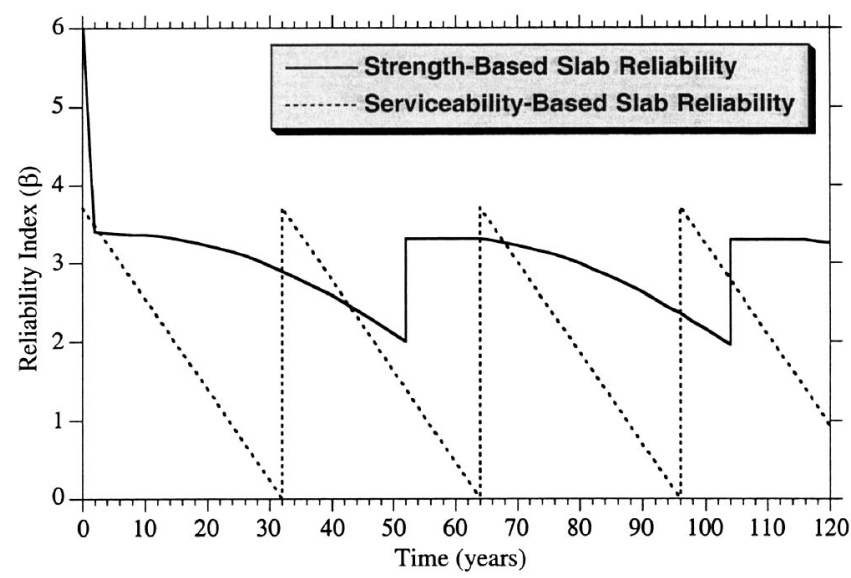

Fig. 4. Repair strategies for reinforced concrete slab considering strength-based and serviceability-based limit states for service life of 120 years

ment in durability performance of concrete cover). In this case if times to cracking and spalling are fully correlated for each bridge deck then the time for first deck replacement is identical to the time for the next deck replacement and so on.

If the deck is replaced $i_{\text {rep }}$ times during the bridge's service life then the mean present value of deck replacement $\left(C_{\mathrm{PV}}\right)$ is thus

$$
C_{\mathrm{PV}}=\sum_{n=1}^{i_{\text {rep }}} \frac{C_{\text {rep }}}{(1+r)^{t_{n}}}
$$

where $C_{\text {rep }}=$ cost of repair (deck replacement cost for all three spans $=2001$ U.S. $\$ 249,100) ; t_{1}=$ time of first deck replacement; and $r=$ discount rate. It is assumed that costs of design, construction, quality assurance/control, inspections, maintenance, etc. are not influenced by the replacement strategy and so are not needed for a comparative analysis of life-cycle costs. As such, the minimum present value of deck replacement will result in minimum life-cycle costs, and, so for this case, is the criterion for selection of optimal repair strategies. Life-cycle cost analyses assuming deck replacement with improved durability or repairs with varying levels of effectiveness are described elsewhere (e.g., Estes 1997; Estes and Frangopol 2001b; Stewart 2001).

\section{Results: Comparison of Life-Cycle Costs}

Assuming a service life of 120 years, $1.0 \mathrm{~mm}$ limit crack width, and a discount rate of $2 \%$, Fig. 4 shows the comparative results of the slab reliabilities over time with respect to the strength and serviceability limit states using all the data listed earlier. The reliability of the slab with respect to strength falls precipitously during the first year as the number of trucks passing over the bridge increases. As the number of trucks continues to increase over the years, the effect is much less as the peak live load approaches an asymptotic value. After the first large drop in reliability, the remainder is mostly attributable to chlorides penetrating the concrete deck and the resulting corrosion of the reinforcing steel. The slab reliability would ordinarily return to its original value of $\beta=6.0$ after full replacement as the traffic count was restarted. It did not in this analysis because the slab was one component in a system reliability analysis of an entire bridge. While the slab was replaced, other components of the bridge were not and a separate load analysis was not conducted for each component on a bridge. The traffic count restarted at zero only when the entire bridge was replaced. The decrease in slab reliability with respect to serviceability appears to be almost linear with time. If the same reliability threshold of $\beta_{T}=2.0$ had been imposed on both limit states, the slab would have been replaced due to serviceability criteria every 12 years.

In general, it might be expected that serviceability reliabilities would always be lower than strength reliabilities. However, in the present case, the relative levels of strength and serviceability reliabilities are influenced by quite separate variables, such as live load model (strength), cross-sectional area of reinforcing steel (strength), cover (serviceability), and so on.

The slab is replaced whenever the strength reliability falls below $\beta=2.0$ or the serviceability limit state falls below $\beta=0.0$. Based on the strength limit state alone, the slab would be replaced at Years 52 and 104 for a present value cost of U.S.\$120,710. When one includes the serviceability limit state in the analysis, the slab would need to be replaced at Years 32, 64, 96, and would reach the end of its useful life at 128 years for a present value cost of U.S. $\$ 239,540$ which is approximately double the cost when serviceability was not considered. An unrealistically optimistic life-cycle cost will result when serviceability is not included in the analysis. Deck replacement at 32 year intervals is not unrealistic given that the deck is exposed to a particularly aggressive environment (de-icing salts) and poor durability concrete as indicated by its low compressive strength (19 MPa—see Table 1). Further, experience shows that considerable deterioration is observed for some structures which are only 20-30 years old (Dunker and Rabbat 1993).

Finally, reliability analyses are highly dependent on the quality of the input and some variables are highly influential. When an alternative live load model was applied to the same problem, the slab was replaced only once at 102 years due to strength constraints at a present value cost of only U.S.\$31,830. However, with an alternative live load model, the target reliability $\left(\beta_{T}\right)$ would have been altered as well, which may have produced more consistent results. The result is only as good as the models which support it. This argues strongly for a periodic inspection program to verify and adjust the input models.

When a system reliability analysis is desired and the user wishes to include both strength and serviceability constraints, Estes and Frangopol (2001a) suggest the use of serviceability flags. The difficulty is that there is no acceptable target system reliability index. Suppose the bridge in this study was modeled as a series system of the ultimate limit state and the serviceability limit state. A target system reliability index of $\beta_{T_{\text {sys }}}=2.0$ would overly constrain the serviceability and cause early and unnecessary repairs. A target system reliability index of $\beta_{T_{\text {sys }}}=0.0$ would allow the possibility of ultimate failure to be unacceptably high. Serviceability flags are a reasonable alternative, but keeping the serviceability and strength components separate as demonstrated in this paper is also viable.

An alternative approach might be to use event-based simulation procedures to model the reliability of a structure subject to multiple limit states since limit state performance would most likely be correlated (e.g., Enright 1998; Stewart and Rosowsky 1998; Enright and Frangopol 1999). For example, a simulation based reliability analysis can include the effect of (1) cover cracking on the acceleration of the corrosion process or (2) cover delamination on the reduction of effective section depth (e.g., $\mathrm{Vu}$ and Stewart 2000). Ultimately, however, serviceability considerations will be important for many structural systems in the estimation of reliabilities and life-cycle cost analyses. 


\section{Conclusions}

1. When performing a life-cycle cost analysis for a typical bridge deck, two performance criteria have to be considered: ultimate strength and serviceability. In this analysis, the variability of material properties, loads, section dimensions, model errors, chloride penetration, and corrosion rates were considered. The analysis has to provide the expected lifetime replacement costs for different repair scenarios.

2. Life-cycle costs for deck replacement based on a serviceability limit state are generally larger than those obtained for a strength limit state. Therefore, an unrealistically optimistic life-cycle cost will result when serviceability is not included in the analysis. It is thus necessary for life-cycle cost analyses to consider multiple limit states.

3. The life-cycle costs based on both strength and serviceability limit states may be used to quantify the additional cost that can be hidden in a single limit state (i.e., strength or serviceability) approach.

4. To develop a rational procedure for life-cycle cost analysis under multiple limit states for reinforced concrete bridge decks, the researchers in lifetime deterioration modeling of concrete structures under aggressive environments and in structural reliability must work in synergy.

\section{References}

Alonso, C., Andrade, C., Rodriguez, J., and Diez, J. M. (1998). "Factors controlling cracking of concrete affected by reinforcement corrosion," Mater. Struct., 31, 435-441.

Cady, P. D. (1985). "Bridge deck rehabilitation decision making." Transportation Research Record 1035, Transportation Research Board, Washington, D.C., 13-20.

Dhir, R. K., Jones, M. R., and McCarthy, M. J. (1994). "PFA concrete: Chloride-induced reinforcement corrosion." Mag. Concrete Res., 46(169), 269-277.

Dunker, K. R., and Rabbat, B. G. (1993). "Why America's bridges are crumbling." Sci. Am., 286, 66-72.

Enright, M. P. (1998). "Time-variant reliability of reinforced concrete bridges under environmental attack." $\mathrm{PhD}$ thesis, Univ. of Colorado, Boulder, Colo.

Enright, M. P., and Frangopol, D. M. (1999). "Reliability-based condition assessment of deteriorating concrete bridges considering load redistribution." Struct. Safety, 21(2), 159-195.

Estes, A. C. (1997). "A system reliability approach to the lifetime optimization of inspection and repair of highway bridges." $\mathrm{PhD}$ thesis, Univ. of Colorado, Boulder, Colo.

Estes, A. C., and Frangopol, D. M. (1999). "Repair optimization of highway bridges using system reliability approach." J. Struct. Eng., 125(7), 766-775.

Estes, A. C., and Frangopol, D. M. (2000). "An optimized lifetime reliability-based inspection program for deteriorating structures." Proc., 8th ASCE Specialty Conf. on Probabilistic Mechanics and Structural Reliability (CD-ROM), A. Kareem, ed., ASCE, Reston, Va.

Estes, A. C., and Frangopol, D. M. (2001a). "Bridge lifetime system reliability under multiple limit states." J. Bridge Eng., 6(6), 523-528.

Estes, A. C., and Frangopol, D. M. (2001b). "Minimum expected costoriented optimal maintenance planning for deteriorating structures: Application to concrete bridge decks." Reliability Eng. Sys. Safety, 73(3), 281-291.

Faber, M. H., and Sorensen, J. D. (1999). "Aspects of inspection planning-Quality and quantity." ICASP8 applications of statistics and probability in civil engineering, R. E. Melchers and M. G. Stewart, eds., Balkema, Rotterdam, The Netherlands, Vol. 2, 739-746.

Frangopol, D. M. (1997). Optimal performance of civil infrastructure systems, ASCE, Reston, Va.
Frangopol, D. M., and Furuta, H., eds. (2001). Life-cycle cost analysis and design of civil infrastructure systems, ASCE, Reston, Va.

Holicky, M., and Mihashi, H. (1999). "Stochastic optimization of concrete cover exposed to carbonation." ICASP8 applications of statistics and probability in civil engineering, R. E. Melchers and M. G. Stewart, eds., Balkema, Rotterdam, The Netherlands, Vol. 1, 279-284.

Liu, Y., and Weyers, R. E. (1998). "Modelling the time-to-corrosion cracking in chloride contaminated reinforced concrete structures." ACI Mater. J., 95(6), 675-681.

Mori, Y., and Ellingwood, B. R. (1994a). "Maintenance reliability of concrete structures. I: Role of inspection and repair." J. Struct. Eng., 120(8), 824-845.

Mori, Y., and Ellingwood, B. R. (1994b). "Maintenance reliability of concrete structures. II: Optimum inspection and repair." J. Struct. Eng., 120(8), 846-862.

Nowak, A. S. (1993). "Live load models for highway bridges." Struct. Safety, 13, 53-66.

Sakai, K., Shimomura, T., and Sugiyama, T. (1999). "Design of concrete structures in the 21st century." Proc., Int. Conf--Controlling Concrete Degradation, Dundee, Scotland.

Sterritt, G., Chryssanthopoulos, M. K., and Shetty, N. K. (2001). "Reliability-based inspection planning for RC highway bridges." Proc., Int. Conf. on Safety, Risk and Reliability-Trends in Engineering, IABSE, Zurich, Switzerland, 1001-1007.

Stewart, M. G. (1998). "Reliability-based bridge design and assessment." Prog. Struct. Eng. Mech., 1(2), 214-222.

Stewart, M. G. (2001). "Spalling risks, durability and life-cycle costs for RC buildings." Proc., Int. Conf. on Safety, Risk, and ReliabilityTrends in Engineering, IABSE, Zurich, Switzerland, 537-542.

Stewart, M. G., Estes, A. C., and Frangopol, D. M. (2002). "Bridge deck replacement strategies and life-cycle cost analyses under multiple limit states." Proc., Int. Conf. on Bridge Safety, Maintenace and Management (CD-ROM), Barcelona, Spain.

Stewart, M. G., and Rosowsky, D. V. (1998). "Structural safety and serviceability of concrete bridges subject to corrosion." J. Infrastruct. Syst., 4(4), 146-155.

Thoft-Christensen, P. (1995). "Advanced bridge management systems." Struct. Eng. Rev., 7(3), 151-163.

Thoft-Christensen, P. (2001). "Corrosion crack based assessment of the life-cycle reliability of concrete structures." Proc, ICOSSAR'01 8th Int. Conf. on Structural Safety and Reliability (CD-ROM), Balkema, Rotterdam, The Netherlands.

Thoft-Christensen, P., Jensen, F. M., Middleton, C. R., and Blackmore, A. (1997). "Assessment of the reliability of concrete slab bridges." Reliability and optimization of structural systems, D. M. Frangopol, R. B. Corotis, and R. Rackwitz, eds., Pergamon, Oxford, United Kingdom, 321-328.

Troive, S., and Sundquist, H. (1998). "Optimisation of design parameters for lowest life-cycle cost of concrete bridges." Proc., 5th Int. Conf. on Short and Medium Span Bridges, Vol. 2, Canadian Society for Civil Engineering, Canada, 1101-1113.

U.S. Army Corps of Engineers Engineering and Design Division (USACE). (1992). "Reliability assessment of navigation structures." ETL 1110-2-532, Dept. of the Army, Washington, D.C.

$\mathrm{Vu}, \mathrm{K}$. A. T. (2003). "Corrosion-induced cracking and spatial timedependent reliability analysis of reinforced concrete structures." $\mathrm{PhD}$ thesis, The Univ. of Newcastle, NSW, Australia.

Vu, K. A. T., and Stewart, M. G. (2000). "Structural reliability of concrete bridges including improved chloride-induced corrosion models." Struct. Safety, 22(4), 313-333.

Vu, K. A. T., and Stewart, M. G. (2001). "Cracking and spalling reliability analysis considering spatial variability for reinforced concrete structures." Proc., ICOSSAR'01 8th Int. Conf. on Structural Safety and Reliability (CD-ROM), Balkema, Rotterdam, The Netherlands.

Vu, K. A. T., and Stewart, M. G. (2002). "Spatial variability of structural deterioration and service life prediction of reinforced concrete bridges." Proc., 1st Int. Conf. on Bridge Maintenance, Safety and Management (CD-ROM), Barcelona, Spain. 